\title{
Sinister self-sacrifice: the contribution of apoptosis to malignancy
}

\author{
Jorine J. L. P. Willems, Benjamin P. Arnold and Christopher D. Gregory* \\ MRC Centre for Inflammation Research, Queen's Medical Research Institute, The University of Edinburgh, Edinburgh, UK \\ *Correspondence: chris.gregory@ed.ac.uk \\ Edited by: \\ Christian Berens, Friedrich-Alexander-Universität Erlangen-Nürnberg, Germany \\ Reviewed by: \\ Patrizia Rovere Querini, Ospedale San Raffaele and Vita-Salute University, Italy \\ Lidija Klampfer, Montefiore Medical Center, USA; Albert Einstein Cancer Center, USA
}

Keywords: apoptosis, inflammation, lactoferrin, phagocytosis, tumor-associated macrophages

Induction of apoptosis is one of the main defenses of the body against cells that have acquired malicious mutations. It may seem counter-intuitive then, that massive cell death is observed in many malignant tumors $(1,2)$. Despite high rates of apoptosis, these tumors continue to grow rapidly. Thus, tumor cell growth must outbalance tumor cell death. Intuitively presumed only to inhibit tumor growth, apoptotic cells may actually promote net tumor growth (3, 4). As long ago as 1956, Revesz showed that cell death can enhance tumor growth (5). Moreover, new studies in progress in our laboratory show that apoptosis in tumor cells promotes growth rates in aggressive B-cell lymphoma.

Cells undergoing apoptosis are difficult to observe in vivo, as they are rapidly cleared by phagocytosis, most obviously by macrophages. Accumulation of macrophages, sometimes engorged with apoptotic cells, is observed in many malignant tumors and is generally associated with poor prognosis $(6,7)$. Inflammatory cells, in particular macrophages, are key elements of the tumor environment, providing support for the continually expanding "rogue" tissue. The tumor microenvironment resembles that of a wound that fails to heal (8), where macrophages not only clear and repair, but also promote tissue regeneration and support. Tumor-associated macrophages (TAM) display a phenotype that is reminiscent of wound-healing macrophages. They have been shown to promote angiogenesis, tissue remodeling, and anti-inflammatory responses, which results in the support of tumor cell growth and metastasis (9-12).

Apoptosis of tumor cells in a growing malignant tissue may therefore be rationalized as a "sinister sacrifice" of some cancer cells that ultimately facilitates cancer progression. We hypothesize that apoptotic cells play a key role in driving oncogenesis, both through the release of soluble and microvesicle-associated signaling factors, as well as through direct interaction with phagocytes. Here we postulate lactoferrin (Lf) as an important signaling factor maintaining an antiinflammatory tumor microenvironment, and stress the importance of apoptotic cell engulfment by macrophages for driving a pro-tumor phenotype in TAM (Figure 1).

\section{DIRECT EFFECTS OF LACTOFERRIN}

Cells undergoing apoptosis release a variety of biologically active "find-me" or "keep-out" signaling factors, including the nucleotides ATP and UTP $(13,14)$, the lipid lysophosphatidylcholine (LPC) (15), as well as the proteins fractalkine (16), $\mathrm{Lf}(17)$, and monocyte chemotactic protein (MCP1) (18). Some of these signaling molecules may be associated with microvesicles, as is the case with the chemokine, fractalkine (16), which may support prolonged biological activity. It has been hypothesized that these find-me signals not only affect chemotaxis and phagocytosis, but may also have additional pleiotropic biological effects. Indeed, ATP released by apoptotic cells increased binding of apoptotic cells to macrophages (19). Furthermore, fractalkine has been shown to stimulate pro-survival and growth-promoting effects $(20,21)$ and was found to cause the expression of milk fat globule epidermal growth factor (MFG-E8) on macrophages, which leads to enhanced apoptotic cell clearance (22).
Lactoferrin was identified in our laboratory to be released from apoptotic cells. Lf is produced de novo by a diverse range of cells stimulated to undergo apoptosis in vitro (17). This $80 \mathrm{kDa}$ ironbinding glycoprotein is well-documented to have immunomodulatory, antimicrobial, anti-inflammatory, and trophic activities (23-26). We propose that $\mathrm{Lf}$ is another pleiotropic molecule released from apoptotic cells that can regulate the tumor microenvironment. Thus, since it is wellknown that apoptosis is frequent in several types of cancer, particularly high-grade forms (27), it is conceivable that persistence of uncleared apoptotic cells (which may occur through saturation) could enable these cells to become secondarily necrotic with the potential consequences of release of noxious contents via cell lysis leading to activation of pro-inflammatory responses (28). However, most malignant tumors maintain a phenotype that militates against anti-tumor immune and inflammatory responses. Given our previous findings that Lf is released from cells undergoing apoptosis (17), together with our unpublished studies showing that Lf binds to necrotic cells, we suggest that Lf serves to dampen down pro-inflammatory responses resulting from persistent secondarily necrotic cells. In fact, it has been shown that necrotic neutrophil lysates, which contain large quantities of Lf from the secondary granules, are anti-inflammatory, and are able to inhibit the production of proinflammatory cytokines, such as tumor necrosis factor- $\alpha(\mathrm{TNF} \alpha)$, IL6, IL8, and IL1 $\beta$, by macrophages (29). The mechanism through which this is achieved may involve the "mopping up" of necrotic cellreleased pro-inflammatory contents by Lf. 


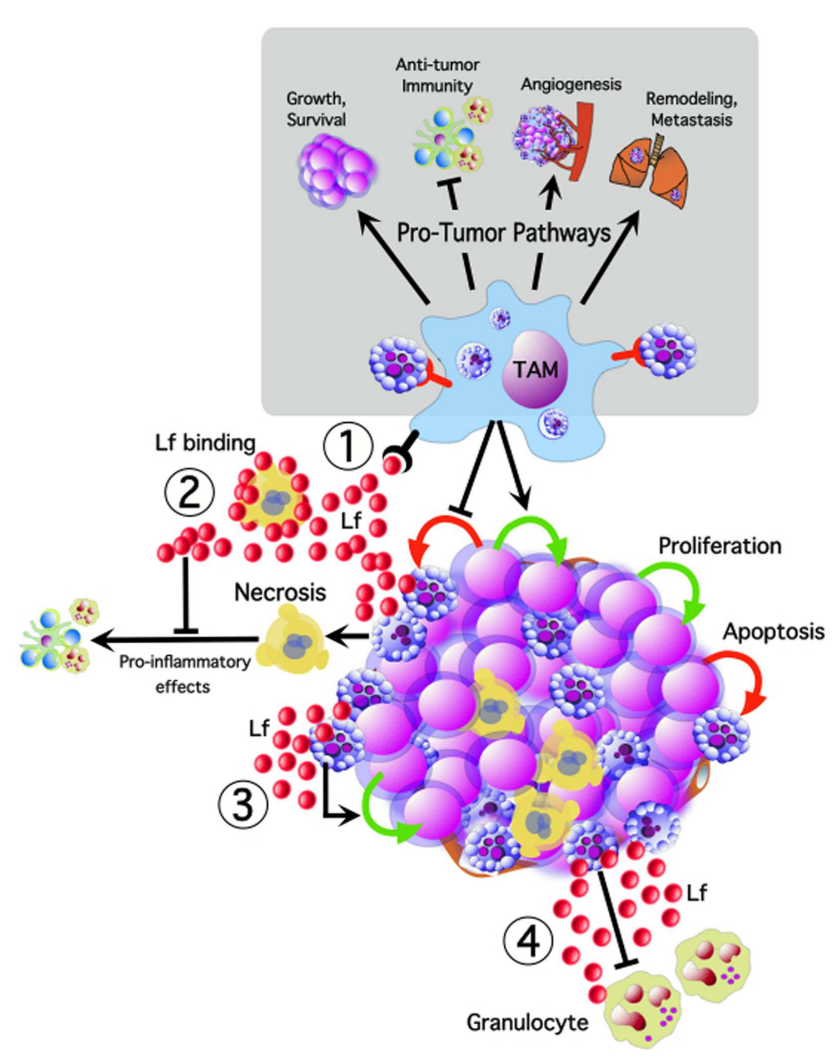

FIGURE 1 | Tumor cell apoptosis potentially activates multiple oncogenic pathways, promoting tumor cell growth and survival, angiogenesis, remodeling, and metastasis, while inhibiting anti-tumor immune responses. We propose that TAM interacting with apoptotic tumor cells are central to many of these pathways. Apoptotic cells release lactoferrin (Lf) which could promote tumor growth and progression by: (1) TAM activation, (2) modulating the inflammatory effects of necrosis, (3) acting as a direct trophic factor, and (4) functioning as a "keep-out" signal to anti-tumor granulocytes.

Lactoferrin has a highly positively charged N-terminal end (30), which is capable of interacting with a variety of proteins and membranes, but can also bind a selection of metal ions as well as iron (31). Furthermore, Lf can interact with lipid A of lipopolysaccharide (LPS) causing the neutralization of LPS-stimulated secretion of pro-inflammatory cytokines by monocytic cells, including TNF $\alpha$, IL1 $\beta$, IL6, and IL8 $(32,33)$. Mopping of noxious contents by Lf may be a final safeguard system to prevent pro-inflammatory responses at sites of high rates of apoptosis. This may not only help maintain the anti-inflammatory environment in tumors, but could also play a role in the resolution of inflammation, where neutrophil activation and death may lead to the release of large quantities of Lf. In addition, in tumors characterized by neutrophil infiltration, the dominant source of biologically active Lf may be derived from neutrophils, rather than apoptotic tumor cells.

Lactoferrin is also known to directly exert anti-inflammatory effects by inhibiting the migration of neutrophils (17) and also by indirectly enhancing the production of anti-inflammatory cytokines including IL4, IL10, and transforming growth factor- $\beta$ (TGF $\beta)(25,26)$. Some studies also suggest that Lf can directly interact in the nuclear factor $\kappa \mathrm{B}(\mathrm{NF} \kappa \mathrm{B})$ pathway interfering with its binding to DNA (33).

These findings point to a possible direct mechanism of Lf for controlling pro- and anti-inflammatory cytokine expression. In high-grade malignancies, these effects of Lf could help moderate anti-tumor inflammatory and immune responses, allowing continued malignant growth. The pro-tumor effects of Lf are likely to be context dependent, however, since Lf has been shown to have proinflammatory, immunostimulatory, and cell growth-inhibitory effects (34-36) as well as anti-inflammatory and trophic properties. An open, and important question is whether Lf is released by dying tumor cells as a consequence of anti-tumor therapy and, if so, whether it has properties which could ultimately confound - or alternatively facilitate - long-term therapeutic efficacy. Again, the significance of Lf may be tissue context dependent.

\section{EFFECTS OF PHAGOCYTES INTERACTING WITH APOPTOTIC TUMOR CELLS}

In addition to the release of signaling factors, interaction of apoptotic cells with phagocytes also provides opportunities for regulating tumor cell growth. TAM are the most important phagocytes of apoptotic tumor cells in most cancers, and often prominently display engulfed remnants of apoptotic cells $(2,37,38)$. Current work in our laboratory indicates that the TAM of aggressive B-cell lymphoma show upregulated expression of receptors involved in the recognition and engulfment of apoptotic cells. Furthermore, recent studies in mice have shown that radiotherapy, one of the most important anti-cancer treatment strategies, can enhance tumor cell repopulation in vivo, through the induction of apoptosis (4). Such effects may be mediated via responses of macrophages that accumulate as a result of the massive radiationinduced apoptosis as previously proposed (39). Apart from preventing the build-up of free apoptotic cells, removal of apoptotic cells by phagocytosis may therefore drive the pro-tumor activation status of TAM.

Engulfment of apoptotic cells by macrophages has been found to activate downstream signaling pathways that cause the up-regulation and secretion of anti-inflammatory mediators such as IL10, and TGF $\beta$, and the down-regulation of pro-inflammatory mediators such as IL6, IL8, IL12, and TNF $\alpha$ (40-43). Furthermore, incubation of phagocytes with apoptotic cells reduces the effects of LPS, increasing release of IL10, while reducing TNF $\alpha$, IL1 $\beta$, and IL12 release. Blocking apoptotic cell engulfment can prevent these responses (44). As well as enhancing anti-inflammatory effects, apoptotic cells have also been shown to promote tumor 
growth and angiogenesis. Phagocytes can release growth factors upon engulfment of apoptotic cells, including VEGF (45), and apoptotic cells can induce angiogenesis via electrostatic effects (46).

Given the abilities of apoptotic cells to induce anti-inflammatory signaling, angiogenesis, and the release of growth factors by TAM, it will be important to determine to what extent they influence additional pro-tumor macrophage properties such as matrix remodeling, invasion, and metastasis.

\section{CONCLUSION}

We propose that the apoptotic cell contributes markedly to the conditioning of the tumor microenvironment. Here, we suggest that Lf released from apoptotic cells could contribute to the anti-inflammatory state of the tumor microenvironment. Furthermore, engagement of apoptotic cells by macrophages may also inhibit anti-tumor inflammatory and immune responses, as well as promote tumor cell growth, angiogenesis, and tissue remodeling. These normal, physiological effects of apoptosis endow this fundamental cell death process with regulated and homeostatic properties that permit tissue turnover, organogenesis, and wound healing. However, these properties may be hijacked in malignant disease in order to facilitate cancer progression.

Understanding the complexity of the signaling of apoptotic tumor cells to viable tumor cells, macrophages, and other elements of the tumor environment will be key to improving tumor treatment outcomes and to prevent metastasis, by targeting the interaction of the host with apoptotic cancer cells. This is especially important since most anti-cancer therapies are designed to induce apoptosis of malignant cells, which, without inhibition of these interactions, could ultimately facilitate tumor repopulation.

\section{ACKNOWLEDGMENTS}

Work in the authors' laboratory is supported by Leukaemia and Lymphoma Research, the Medical Research Council (UK), and the Biotechnology and Biological Sciences Research Council (UK).

\section{REFERENCES}

1. Wyllie AH. The biology of cell death in tumours. Anticancer Res (1985) 5(1):131-6.
2. Harris NL. A practical approach to the pathology of lymphoid neoplasms: a revised EuropeanAmerican classification from the International Lymphoma Study Group. Important Adv Oncol (1995):111-40.

3. Gregory CD, Pound JD. Cell death in the neighbourhood: direct microenvironmental effects of apoptosis in normal and neoplastic tissues. J Pathol (2010) 223(2):177-94. doi:10.1002/path.2792

4. Huang Q, Li F, Liu X, Li W, Shi W, Liu F-F, et al. Caspase 3-mediated stimulation of tumor cell repopulation during cancer radiotherapy. Nat Med (2011) 17(7):860-6. doi:10.1038/nm.2385

5. Revesz L. Effect of tumour cells killed by x-rays upon the growth of admixed viable cells. Nature (1956) 178(4547):1391-2. doi:10.1038/1781391a0

6. Balkwill F, Mantovani A. Inflammation and cancer: back to Virchow? Lancet (2001) 357(9255):539-45. doi:10.1016/S0140-6736(00)04046-0

7. Coussens LM, Werb Z. Inflammation and cancer. Nature (2002) 420(6917):860-7. doi:10.1038/ nature 01322

8. Dvorak HF. Tumors: wounds that do not heal: similarities between tumor stroma generation and wound healing. $N$ Engl J Med (1986) 315(26):1650-9. doi:10.1056/NEJM198612253152606

9. Sica A, Larghi P, Mancino A, Rubino L, Porta C, Totaro MG, et al. Macrophage polarization in tumour progression. Semin Cancer Biol (2008) 18(5):349-55. doi:10.1016/j. semcancer.2008.03.004

10. Biswas SK, Mantovani A. Macrophage plasticity and interaction with lymphocyte subsets: cancer as a paradigm. Nat Immunol (2010) 11(10):889-96. doi:10.1038/ni.1937

11. Senovilla L, Vacchelli E, Galon J, Adjemian S, Eggermont A, Fridman WH, et al. Trial watch: prognostic and predictive value of the immune infiltrate in cancer. Oncoimmunology (2012) 1(8):1323-43.

12. Qian B-Z, Pollard JW. Macrophage diversity enhances tumor progression and metastasis. Cell (2010) 141(1):39-51. doi:10.1016/j.cell.2010.03. 014

13. Elliott MR, Chekeni FB, Trampont PC, Lazarowski ER, Kadl A, Walk SF, et al. Nucleotides released by apoptotic cells act as a find-me signal to promote phagocytic clearance. Nature (2009) 461(7261):282-6. doi:10.1038/nature08296

14. Chekeni FB, Elliott MR, Sandilos JK, Walk SF, Kinchen JM, Lazarowski ER, et al. Pannexin 1 channels mediate "find-me" signal release and membrane permeability during apoptosis. Nature (2010) 467(7317):863-7. doi:10.1038/ nature 09413

15. Lauber K, Bohn E, Kröber SM, Xiao Y-J, Blumenthal SG, Lindemann RK, et al. Apoptotic cells induce migration of phagocytes via caspase3-mediated release of a lipid attraction signal. Cell (2003) 113(6):717-30. doi:10.1016/S00928674(03)00422-7

16. Truman LA, Ford CA, Pasikowska M, Pound JD, Wilkinson SJ, Dumitriu IE, et al. CX3CL1/fractalkine is released from apoptotic lymphocytes to stimulate macrophage chemotaxis. Blood (2008) 112(13):5026-36. doi:10.1182/blood-2008-06-162404

17. Bournazou I, Pound JD, Duffin R, Bournazos S, Melville LA, Brown SB, et al. Apoptotic human cells inhibit migration of granulocytes via release of lactoferrin. J Clin Invest (2009) 119(1):20-32. doi:10.1172/JCI36226

18. Kobara M, Sunagawa N, Abe M, Tanaka N, Toba $\mathrm{H}$, Hayashi $\mathrm{H}$, et al. Apoptotic myocytes generate monocyte chemoattractant protein-1 and mediate macrophage recruitment. J Appl Physiol (2008) 104(3):601-9. doi:10.1152/japplphysiol. 00254.2007

19. Marques-da-Silva C, Burnstock G, Ojcius DM, Coutinho-Silva R. Purinergic receptor agonists modulate phagocytosis and clearance of apoptotic cells in macrophages. Immunobiology (2011) 216(1-2):1-11. doi:10.1016/j.imbio.2010.03.010

20. Boehme SA, Lio FM, Maciejewski-Lenoir D, Bacon $\mathrm{KB}$, Conlon PJ. The chemokine fractalkine inhibits Fas-mediated cell death of brain microglia. J Immunol (2000) 165(1):397-403. doi:10.4049/ jimmunol.165.1.397

21. White GE, Tan TC, John AE, Whatling C, McPheat WL, Greaves DR. Fractalkine has antiapoptotic and proliferative effects on human vascular smooth muscle cells via epidermal growth factor receptor signalling. Cardiovasc Res (2010) 85(4):825-35. doi:10.1093/cvr/cvp341

22. Miksa M, Amin D, Wu R, Ravikumar TS, Wang P. Fractalkine-induced MFG-E8 leads to enhanced apoptotic cell clearance by macrophages. $\mathrm{Mol}$ Med (2007) 13(11-12):553-60. doi:10.2119/200700019.Miksa

23. Chapple DS, Mason DJ, Joannou CL, Odell EW, Gant V, Evans RW. Structure-function relationship of antibacterial synthetic peptides homologous to a helical surface region on human lactoferrin against Escherichia coli serotype O111. Infect Immun (1998) 66(6):2434-40.

24. Naot D, Callon KE, Grey A, Cooper GJ, Reid IR, Cornish J. A potential role for adrenomedullin as a local regulator of bone growth. Endocrinology (2001) 142(5):1849-57. doi:10.1210/endo.142. 5.8152

25. Togawa J-I, Nagase H, Tanaka K, Inamori $M$, Nakajima A, Ueno $\mathrm{N}$, et al. Oral administration of lactoferrin reduces colitis in rats via modulation of the immune system and correction of cytokine imbalance. J Gastroenterol Hepatol (2002) 17(12):1291-8. doi:10.1046/j.1440-1746. 2002.02868.x

26. Zimecki M, Artym J, Chodaczek G, Kocieba M, Kruzel M. Effects of lactoferrin on the immune response modified by the immobilization stress. Pharmacol Rep (2005) 57(6):811-7.

27. Wyllie AH. Apoptosis and the regulation of cell numbers in normal and neoplastic tissues: an overview. Cancer Metastasis Rev (1992) 11(2):95-103. doi:10.1007/BF00048057

28. Savill J, Fadok V, Henson P, Haslett C. Phagocyte recognition of cells undergoing apoptosis. Immunol Today (1993) 14(3):131-6. doi:10.1016/ 0167-5699(93)90215-7y

29. Miles K, Clarke DJ, Lu W, Sibinska Z, Beaumont PE, Davidson DJ, et al. Dying and necrotic neutrophils are anti-inflammatory secondary to the release of alpha-defensins. J Immunol (2009) 183(3):2122-32. doi:10.4049/jimmunol. 0804187

30. Bellamy W, Takase M, Yamauchi K, Wakabayashi $\mathrm{H}$, Kawase K, Tomita M. Identification of the 
bactericidal domain of lactoferrin. Biochim Biophys Acta (1992) 1121(1-2):130-6. doi:10.1016/ 0167-4838(92)90346-F

31. Baker EN, Baker HM. Molecular structure, binding properties and dynamics of lactoferrin. Cell Mol Life Sci (2005) 62(22):2531-9. doi:10.1007/ s00018-005-5368-9

32. Appelmelk BJ, An YQ, Geerts M, Thijs BG, de Boer HA, MacLaren DM, et al. Lactoferrin is a lipid A-binding protein. Infect Immun (1994) 62(6):2628-32.

33. Håversen L, Ohlsson BG, Hahn-Zoric M, Hanson LA, Mattsby-Baltzer I. Lactoferrin downregulates the LPS-induced cytokine production in monocytic cells via NF-kappa B. Cell Immunol (2002) 220(2):83-95. doi:10.1016/S0008-8749(03) 00006-6

34. Curran CS, Demick KP, Mansfield JM. Lactoferrin activates macrophages via TLR4-dependent and -independent signaling pathways. Cell Immunol (2006) 242 (1):23-30. doi:10.1016/j.cellimm.2006. 08.006

35. de la Rosa G, Yang D, Tewary P, Varadhachary A, Oppenheim JJ. Lactoferrin acts as an alarmin to promote the recruitment and activation of APCs and antigen-specific immune responses. JImmunol (2008) 180(10):6868-76. doi:10.4049/jimmunol. 180.10 .6868

36. Damiens E, El Yazidi I, Mazurier J, Duthille I, Spik G, Boilly-Marer Y. Lactoferrin inhibits G1 cyclin-dependent kinases during growth arrest of human breast carcinoma cells. J Cell Biochem (1999) 74(3):486-98. doi:10.1002/(SICI)1097-4644(19990901)74: 3<486::AID-JCB16>3.0.CO;2-6
37. Ogden CA, Pound JD, Batth BK, Owens S, Johannessen I, Wood K, et al. Enhanced apoptotic cell clearance capacity and $\mathrm{B}$ cell survival factor production by IL-10-activated macrophages: implications for Burkitt's lymphoma. J Immunol (2005) 174(5):3015-23. doi:10.4049/jimmunol. 174.5.3015

38. Hori M, Xiang S, Qi C-F, Chattopadhyay SK, Fredrickson TN, Hartley JW, et al. Non-Hodgkin lymphomas of mice. Blood Cells Mol Dis (2001) 27(1):217-22. doi:10.1006/bcmd.2000.0375

39. Lauber K, Muñoz LE, Berens C, Jendrossek V, Belka C, Herrmann M. Apoptosis induction and tumor cell repopulation: the yin and yang of radiotherapy. Radiat Oncol (2011) 6(1):176. doi:10.1186/1748717X-6- 176

40. Huynh ML. Phosphatidylserine-dependent ingestion of apoptotic cells promotes TGF-betal secretion and the resolution of inflammation. J Clin Invest (2002) 109(1):41-50. doi:10.1172/ JCI200211638

41. Napirei M, Mannherz HG. Molecules involved in recognition and clearance of apoptotic/necrotic cells and cell debris. In: Krysko DV, Vandenabeele P, editors. Phagocytosis of Dying Cells: From Molecular Mechanisms to Human Disease. Dordrecht: Springer Verlag (2009). p. 103-45.

42. Grimsley C. Cues for apoptotic cell engulfment: eat-me, don't eat-me and come-get-me signals. Trends Cell Biol (2003) 13(12):648-56. doi:10. 1016/j.tcb.2003.10.004

43. Wu Y, Tibrewal N, Birge RB. Phosphatidylserine recognition by phagocytes: a view to a kill. Trends Cell Biol (2006) 16(4):189-97. doi:10.1016/j.tcb. 2006.02.003
44. Voll RE, Herrmann M, Roth EA, Stach C, Kalden JR, Girkontaite I. Immunosuppressive effects of apoptotic cells. Nature (1997) 390(6658):350-1. doi:10.1038/37022

45. Golpon HA. Life after corpse engulfment: phagocytosis of apoptotic cells leads to VEGF secretion and cell growth. FASEB J (2004) 18(14):1716-8. doi:10.1096/fj.04-1853fje

46. Weihua Z. Apoptotic cells initiate endothelial cell sprouting via electrostatic signaling. Cancer Res (2005) 65(24):11529-35. doi:10.1158/0008-5472. CAN-05-2718

Conflict of Interest Statement: The authors declare that the research was conducted in the absence of any commercial or financial relationships that could be construed as a potential conflict of interest.

Received: 08 May 2014; accepted: 13 June 2014; published online: 04 July 2014.

Citation: Willems JJLP, Arnold BP and Gregory CD (2014) Sinister self-sacrifice: the contribution of apoptosis to malignancy. Front. Immunol. 5:299. doi: 10.3389/fimmu.2014.00299

This article was submitted to Inflammation, a section of the journal Frontiers in Immunology.

Copyright (c) 2014 Willems, Arnold and Gregory. This is an open-access article distributed under the terms of the Creative Commons Attribution License (CC BY). The use, distribution or reproduction in other forums is permitted, provided the original author(s) or licensor are credited and that the original publication in this journal is cited, in accordance with accepted academic practice. No use, distribution or reproduction is permitted which does not comply with these terms. 